\title{
Marketing of Dietetic Products for Infants and Young Children in Europe Three Decades after Adoption of the International Code of Marketing of Breast Milk Substitutes
}

\author{
Berthold Koletzko \\ Hauner Children's Hospital, University of Munich Medical Centre, Munich, Germany
}

Three decades ago the 'International Code of Marketing of Breast Milk Substitutes' (the Code) was adopted by the 33rd World Health Assembly, the decision-making body of the World Health Organization [1]. The Code aims to protect and promote breast feeding and to ensure ethical approaches to marketing of infant formulae and other foods that are presented as a partial or total replacement for breast milk. These goals are as timely today as ever before given the much increased evidence on the importance of infant feeding for growth, development, and long-term health well into adulthood [2]. Breast feeding is widely recognized as the ideal form of infant feeding, providing multiple benefits for child health, affecting not only immediate health outcomes such as prevention of infectious gastroenteritis but also important long-term outcomes such as a reduced risk of obesity and atopic eczema, and enhanced cognitive development [3-8]. Thus, breast feeding should be actively promoted, protected, and supported. The Code supports the protection of breastfeeding and stipulates that there should be no advertising or other form of promotion of breast milk substitutes to the general public and that manufacturers and distributors should not provide to families, directly or indirectly, samples of such products or other gifts of uten- sils which may promote the use of breast milk substitutes or bottle feeding. It is stated that the presentation of products must clearly express the superiority of breast feeding and that no pictures or text may be used that idealize the use of infant formula. The Code obliges the member states of the World Health Assembly to take appropriate measures to promote and implement these principles.

Countries around the world have implemented measures to promote the principles and practices laid down in the Code [9]. Also the Global Infant Formula Standard of the Codex Alimentarius indicates that the recommendations made in the Code should be taken into account [10]. With regard to Europe, all of the member states of the European Union at the World Health Assembly voted in favor of adoption of the Code [11]. Consequently, the European Directive on infant formulae and follow-on formulae established that 'the rules of labeling and advertising for these products should be in conformity with the principles and the aims of the International Code of Marketing of Breast Milk Substitutes adopted by the 34th World Health Assembly' in an effort to provide better protection for the health of infants [12]. However, the current practice in Europe in this regard is far from satisfactory and not in agreement with the European legislation.

\section{KARGER}

Fax +4161306 1234 E-Mail karger@karger.ch www.karger.com

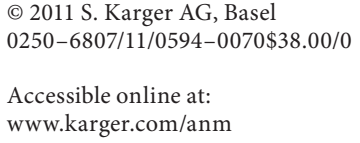

Prof. Berthold Koletzko, MD

Hauner Children's Hospital, University of Munich Medical Centre Lindwurmstrasse 4

DE-80337 Munich (Germany)

Tel. +498951602826, E-Mail office.koletzko@med.uni-muenchen.de 
Serious infringements of the Code are common, and governments often have not taken responsibility for monitoring and enforcement of the Code [11].

It is of particular concern that current practices of marketing of dietetic products for infants and young children are even deteriorating in increasingly violating appropriate professional and ethical standards. This shall be demonstrated here by a few recent examples of completely unacceptable and irresponsible marketing activities observed in Austria and Germany.

For example, a global infant formula manufacturer recently initiated and manipulated the development of recommendations on young child feeding signed by a group of pediatricians in Austria, which were then presented to the public and to pediatric organizations as if they had been independently developed, without disclosing the actual involvement of a public relations agency that was contracted and paid by the global infant formula manufacturer to draft the recommendations. Not surprisingly, these recommendations, initiated and financed by the global infant formula manufacturer, support the use of growing-up milks produced by this company. The printed recommendations have since been distributed by this company along with glossy brochures and a mouse pad advertising these very products, as well as through press activities and seminars for health care professionally organized and financed by the same company, without transparent disclosure of the role of interested parties in the development of these recommendations. Obviously this violates generally accepted professional and ethical standards.

Furthermore, a major infant formula manufacturer distributes free packages with an infant feeding bottle and nipple in a box labeled with the company advertisements to parents of infants aged 4-6 weeks. This infant formula manufacturer also distributes free packages of infant formula samples to doctors and midwives for distribution to young families, which was previously demonstrated to adversely affect breastfeeding rates and duration [11]. This is clearly an attempt to undermine breast feeding of infants during the first weeks and months of life while promoting the sales of infant formula, and it represents an unethical marketing practice in obvious violation of the WHO code as well as the European and national legislation.

Moreover, a major infant formula manufacturer markets infant formula and follow-on formula products labeled on the front of the package with the wording 'close to the model of human milk'. In advertisements in magazines and in television spots addressing the general pub- lic, a woman breastfeeding her baby is depicted, and the accompanying text explains 'Breastfeeding is a wonder of nature. We have come much closer to this wonder through a big step'. This statement is factually wrong and misleads consumers, because the composition of these products with an added oligosugar and a strain of lactic acid producing bacteria is not anywhere close to the composition of human milk, and there is not even any conclusive scientific evidence available to demonstrate the safety or potential benefits of these products. Moreover, promoting these formulae for infants as being similar to human milk, in violation of the WHO Code and the European and national legislation, may lead parents to believe that these formulae would have a benefit comparable to that of human milk and hence can undermine breastfeeding.

Sadly, the protests of the German Society of Pediatrics, the German Professional Society of Pediatricians, and the German National Breastfeeding Committee to manufacturers and to the national and European infant formula manufacturer association have not lead to any satisfactory response or change in practice. This is surprising since it would appear to be in the long-term interest of the industry itself to comply with appropriate ethical standards because only then can they expect to achieve sustainable commercial success. It is perhaps even more frustrating that the food safety authorities charged with surveillance of compliance with the dietetic food law have been informed about the violations against valid legislation but so far have not acted at all.

One can only agree with a recent comment by Prof. Stewart Forsyth who wrote that 'there is need for a more transparent governance structure that has clearly defined responsibilities for ensuring that there are reliable and sustainable systems in place that will underpin the effective delivery of the Code' [13]. Three decades after the unanimous adoption of the International Code of Marketing of Breast Milk Substitutes, it is high time that governments of European countries accept their responsibility to consistently implement the principles of the Code in order to support the health and well-being of our children. 


\section{References}

1 World Health Organisation: International Code of Marketing of Breast-milk Substitutes. Geneva, WHO, 1981.

-2 Hanley B, Dijane J, Fewtrell M, Grynberg A, Hummel S, Junien C, Koletzko B, Lewis S, Renz H, Symonds M, et al: Metabolic imprinting, programming and epigenetics - a review of present priorities and future opportunities. Br J Nutr 2010;104(suppl 1):S1S25.

-3 Agostoni C, Braegger C, Decsi T, Kolacek S, Koletzko B, Michaelsen KF, Mihatsch W, Moreno LA, Puntis J, Shamir R, et al: Breastfeeding: a commentary by the ESPGHAN Committee on Nutrition. J Pediatr Gastroenterol Nutr 2009;49:112-125.

-4 Koletzko B, von Kries R, Closa R, Escribano J, Scaglioni S, Giovannini M, Beyer J, Demmelmair H, Anton B, Gruszfeld D, et al: Can infant feeding choices modulate later obesity risk? Am J Clin Nutr 2009;89:1502S-1508S.
5 Van Rossum CMT, Büchner FL, Hoekstra J: Quantification of health effects of breastfeeding: review of the literature and model simulation. RIVM Report 350040001. Bilthoven, RIVM, 2005.

6 Agency for Healthcare Research and Quality: Breastfeeding and maternal and infant health outcomes in developed countries. AHRQ Publication 07-E007. Rockville, AHRH, 2007.

7 Steer CD, Davey Smith G, Emmett PM, Hibbeln JR, Golding J: FADS2 polymorphisms modify the effect of breastfeeding on child IQ. PLoS One 2010;5:e11570.

8 Rebhan B, Kohlhuber M, Schwegler U, Fromme H, Abou-Dakn M, Koletzko BV: Breastfeeding duration and exclusivity associated with infants' health and growth: data from a prospective cohort study in Bavaria, Germany. Acta Paediatr 2009;98:974-980.

9 World Health Organisation: The International Code of Marketing of Breast-milk Subsitutes: A Common Review and Evaluation Framework. Geneva, WHO, 1997.
10 Codex Alimentarius Commission: Standard for infant formula and formulas for special medical purposes intended for infants (CODEX STAN 72 - 1981), last revised 2007. Rome, Codex Alimentarius Commission, 2007.

11 Cattaneo A, Yngve A, Koletzko B, Guzman LR: Protection, promotion and support of breast-feeding in Europe: current situation. Public Health Nutr 2005;8:39-46.

12 European Commission: Commission Directive 2006/141/EC of 22 December 2006 on infant formulae and follow-on formulae and amending Directive 1999/21/EC. Official J Eur Union 2006, p. L 401/1.

13 Forsyth JS: International code of marketing of breast-milk substitutes - three decades later time for hostilities to be replaced by effective national and international governance. Arch Dis Child 2010;95:769-770. 